\title{
A rare case of multiple endocrine neoplasia type 1 initially presenting as an asymptomatic, huge mediastinal mass: case report
}

\author{
Ji Eun Jun, You-Cheol Hwang, Kyu Jeong Ahn, Ho Yeon Chung and In-Kyung Jeong ${ }^{*}$ (10
}

\begin{abstract}
Background: Multiple endocrine neoplasia type 1 (MEN1) is a rare inherited syndrome that concurrently involves various endocrine glands. We report a rare case of MEN1 in a 43-year-old man whose first manifestation was an asymptomatic mediastinal mass.

Case presentation: A 13-cm-sized mediastinal mass was diagnosed as an atypical thymic carcinoid by computed tomography and percutaneous needle biopsy. In addition, hypercalcemia from a left inferior parathyroid hyperplasia, and a non-functioning gastric neuroendocrine tumor seen on esophagogastroduodenoscopy were found. Therefore, the patient was clinically diagnosed with MEN1 syndrome, and underwent surgical resection of thymic carcinoid tumor after pre-operative concurrent chemoradiation therapy to decrease tumor size and volume. Parathyroid lesion and gastric neuroendocrine tumor were also removed. Finally, a MEN1 gene mutation was observed in the patient and his 7-year-old son.

Conclusion: Despite its rare occurrence, thymic carcinoid tumor should be considered as a MEN1-associated tumor and necessitates screening of other endocrine glands. Thymic carcinoid tumor carries a poor prognosis in patients with MEN1, and thus it needs to be carefully monitored even after radical excision.
\end{abstract}

Keywords: Case report, Multiple endocrine neoplasia, MEN1, Thymic carcinoid tumor

\section{Background}

Multiple endocrine neoplasia type 1 (MEN 1) is a rare hereditary syndrome characterized by a predisposition for neoplasms involving two or more endocrine glands, primarily of parathyroid, anterior pituitary, and enteropancreatic origin [1]. Other endocrine tumors of MEN1 include carcinoid tumors, adrenocortical tumors, and rarely, pheochromocytoma [2]. Among them, thymic carcinoid tumor is less common, with an incidence of

\footnotetext{
*Correspondence: jik1016@naver.com

Department of Endocrinology and Metabolism, Kyung Hee University Hospital at Gangdong, Kyung Hee University School of Medicine, 892 Dongnam-ro, Gangdong-gu, Seoul 05278, Republic of Korea
}

$3.6-8.4 \%$, and only $25 \%$ of all thymic carcinoid tumors occur in patients with MEN1 [3]. Despite its low incidence, MEN1-associated thymic carcinoid tumor leads to poor prognosis due to its more aggressive nature and strong potential for metastasis $[4,5]$. Herein, we report a case of MEN1 in a patient with an asymptomatic and huge mediastinal mass as an initial presentation.

\section{Case presentation}

A 43-year-old man was admitted to the hospital due to an enlarged mediastinum incidentally observed on chest $x$-ray during a routine health check-up (Fig. 1a). The patient was a 20 pack-year current smoker and had

(c) The Author(s). 2021 Open Access This article is licensed under a Creative Commons Attribution 4.0 International License, which permits use, sharing, adaptation, distribution and reproduction in any medium or format, as long as you give appropriate credit to the original author(s) and the source, provide a link to the Creative Commons licence, and indicate if changes were made. The images or other third party material in this article are included in the article's Creative Commons licence, unless indicated otherwise in a credit line to the material. If material is not included in the article's Creative Commons licence and your intended use is not permitted by statutory regulation or exceeds the permitted use, you will need to obtain permission directly from the copyright holder. To view a copy of this licence, visit http://creativecommons.org/licenses/by/4.0/ The Creative Commons Public Domain Dedication waiver (http://creativecommons.org/publicdomain/zero/1.0/) applies to the data made available in this article, unless otherwise stated in a credit line to the data. 

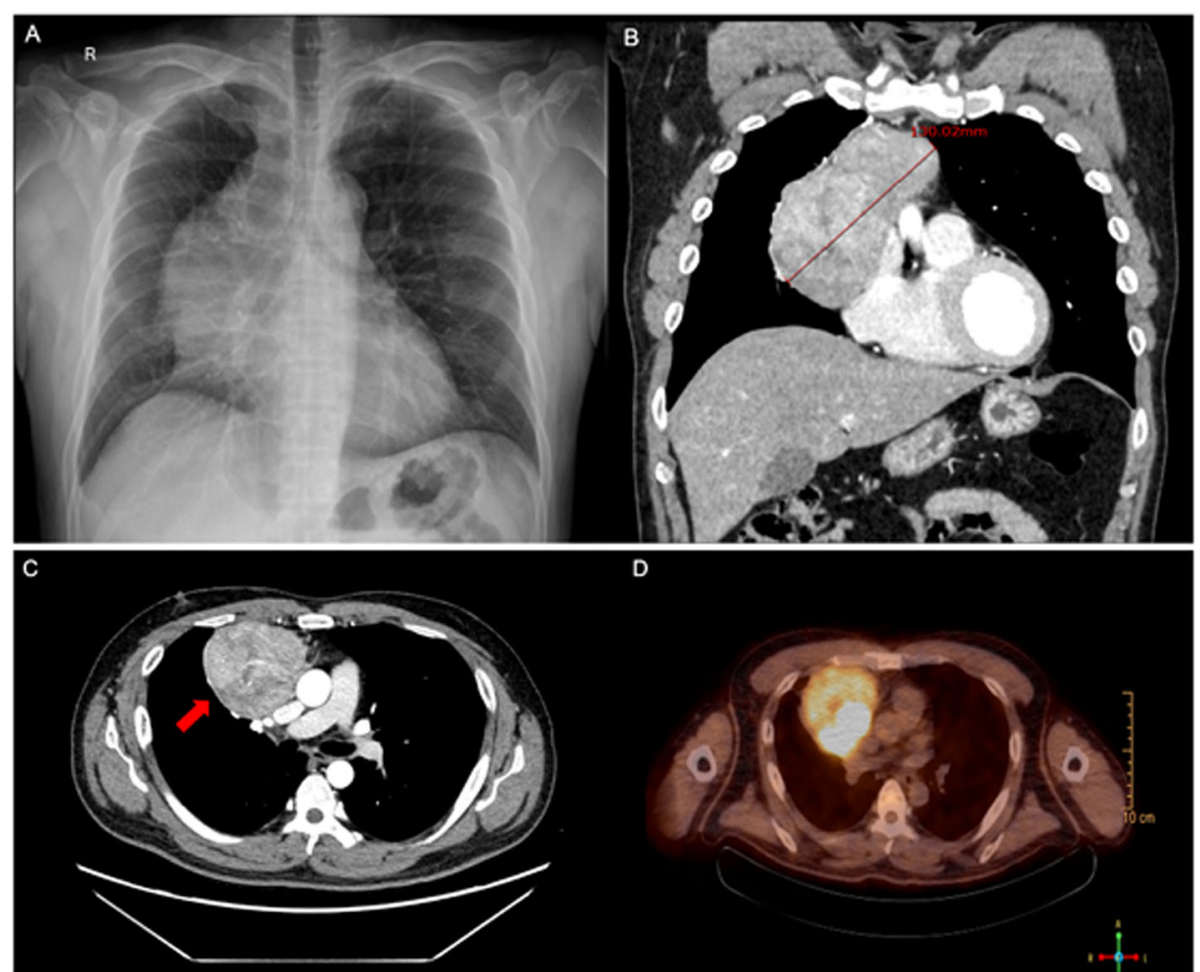

Fig. 1 Images of the mediastinal mass. a Chest X-ray showing a lobulated right cardiomediastinal contour. b Contrast enhanced computed tomography (CT) showing a 13-cm-sized mediastinal mass in the sagittal plane (red arrow). c CT showing an anterior mediastinal mass invading the superior vena cava and pericardium (red arrow). d Fluorodeoxyglucose (FDG) positron emission tomography showing intense FDG uptake within the mass, with an SUVmax of 10.1

recently diagnosed with hypertension. His father died suddenly in his 40s for unknown reasons, but there was no history of cancer, or chronic disease in his family or relatives. There was no persional or family history of kidney stones as well. At admission, the patient was asymptomatic, and physical examination and vital signs were unremarkable; Swelling of the face, neck, or upper body and dyspnea or distended neck veins were also not observed. No cutaneous findings were reported.

Enhanced chest computed tomography (CT) showed an anterior mediastinal mass invading the superior vena cava and pericardium that measured approximately $13.0 \times$ $8.0 \times 6.0 \mathrm{~cm}$ in size (Fig. $1 \mathrm{~b}$ and c). Fluorodeoxyglucosepositron emission tomography indicated a hypermetabolic (SUVmax $=10.6$ ) mediastinal mass without additional uptake by other organs or regional lymph nodes (Fig. 1d).

Laboratory results demonstrated elevated fasting plasma glucose of $128 \mathrm{mg} / \mathrm{dL}$ and $\mathrm{HbA1c}$ of $8.6 \%$, which were sufficient to diagnose diabetes. Plasma insulin was $27.5 \mu \mathrm{U} /$ $\mathrm{mL}$ (normal range, 1.4-12.4), fasting C-peptide was 4.85 $\mathrm{ng} / \mathrm{mL}$ (normal range, 0.78-5.19), and glucagon was increased to $431.7 \mathrm{pg} / \mathrm{mL}$ (normal range, 25-250). Serum calcium level was slightly elevated at $10.9 \mathrm{mg} / \mathrm{dL}$ (normal range, 8.8-10.6) and albumin-corrected calcium was 10.8 $\mathrm{mg} / \mathrm{dL}$ with a normal phosphorus level of $3.7 \mathrm{mg} / \mathrm{dL}$ (normal range, 2.5-4.5). In the work-up for hypercalcemia, serum intact parathyroid hormone (PTH) level was elevated at $78.7 \mathrm{pg} / \mathrm{mL}$, and recheck level was more increased up to $128 \mathrm{pg} / \mathrm{mL}$ (normal range, 15-65). A 25hydroxy vitamin $\mathrm{D}$ was low at $8.0 \mathrm{ng} / \mathrm{mL}$, and the $24-\mathrm{h}$ urine calcium amount was $300 \mathrm{mg} /$ day. A bone density scan showed anterior-posterior spine L1-4 bone mineral density (BMD) of $0.806 \mathrm{~g} / \mathrm{cm}^{2}$ with a Z-score of -3.6 , left femoral total BMD of $0.969 \mathrm{~g} / \mathrm{cm}^{2}$ with a Z-score of 0.4 , and left femoral neck BMD of $0.959 \mathrm{~g} / \mathrm{cm}^{2}$ with a Z-score of 0.3. Neck ultrasound showed a $1.2 \mathrm{~cm}$ enlarged parathyroid gland (Fig. 2a) and a Tc-99 m sestamibi scan demonstrated focal increased activity at the left lower pole region (Fig. 2b), suggestive of functional parathyroid adenoma.

Abdominal CT (Fig. 3a) found multiple small, lowattenuated lesions in the pancreatic head and body. However, there were no abnormal findings on magnetic resonance imaging (MRI) of the pancreas (Fig. 3b); thus, the pancreatic lesions observed on CT were considered peripancreatic fat infiltrations. Esophagogastroduodenoscopy (Fig. 4) demonstrated a submucosal mass at the antrum of the stomach, which was proven to be a welldifferentiated neuroendocrine tumor (NET). Meanwhile, serum gastrin level was $54.9 \mathrm{pg} / \mathrm{mL}$ (normal range, < 180). 

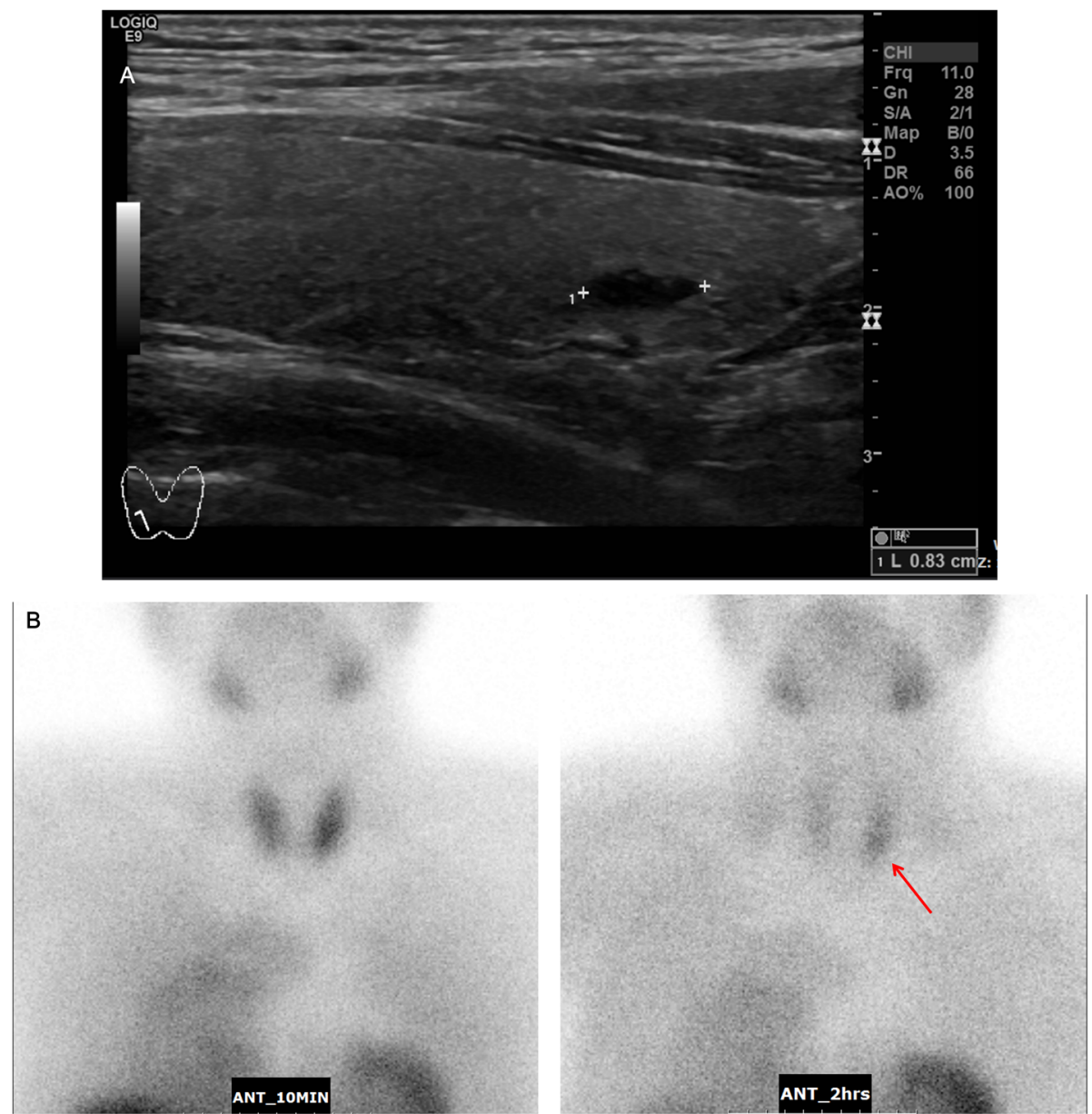

Fig. 2 Images of the parathyroid glands. a The longitudinal scan of neck ultrasound demonstrates a well-defined hypoechoic solid mass posteroinferior to the left lobe of the thyroid gland. b Early and late $99 \mathrm{~m}$ Tc-sestamibi scintigraphy parathyroid scan images of the neck and anterior mediastinum at $10 \mathrm{~min}$ and $2 \mathrm{~h}$, showing increased focal uptake (red arrow) suggestive of left inferior parathyroid adenoma

Evaluations of the pituitary gland revealed a slightly elevated serum prolactin level of $21.9 \mathrm{ng} / \mathrm{mL}$ (normal range, 4.1-18.4), normal thyroid hormones, normal IGF1, normal FSH, normal testosterone, but a low LH level < $0.5 \mathrm{mIU} / \mathrm{mL}$ (normal range, $0.57-12.07$ ). Morning cortisol level was normal $(10.2 \mu \mathrm{g} / \mathrm{dL})$, and serum cortisol was suppressed by a $1 \mathrm{mg}$ overnight dexamethasone. Basal ACTH level was $64.8 \mathrm{pg} / \mathrm{mL}$ (normal range, 4.7-48.8). Sella MRI showed a $0.3 \mathrm{~cm}$, delayed enhancing lesion, which was hard to differentiate between pituitary microadenoma and normal variant of pituitary gland (Fig. 5).

Based on these results, the patient had thymic carcinoid tumor, primary hyperparathyroidism, and gastric NET as a result of MEN1. In genetic testing for MEN1 (Supplementary Fig. 1A and 1B), the patient and his 7year-old son, but not his younger brother, had the same missense mutation (c.634G > A, p.Val215Met) of the MEN1 gene.

For treatment, neoadjuvant concurrent chemoradiotherapy reduced the size of the thymic carcinoid tumor.
Finally, video-assisted thoracoscopic surgery on the thymic carcinoid and left inferior parathyroidectomy were simultaneously performed after 2 months of chemoradiotherapy. Postoperative pathology confirmed the final diagnosis of atypical thymic carcinoid (Fig. 6a) and parathyroid hyperplasia (Fig. 6b). The gastric NET was also removed by endoscopic resection (Fig. 6c). At oneyear postoperative, there has been no tumor recurrence on follow-up chest CT, and serum calcium level and BMD returned to normal, though there was slight elevation in serum PTH level $(72 \mathrm{pg} / \mathrm{mL})$ after having been previously normalized $(28.9 \mathrm{pg} / \mathrm{mL})$. Serum prolactin level $(20.3 \mathrm{ng} / \mathrm{mL})$ did not change during the first postoperative year.

\section{Discussion and conclusions}

This case was diagnosed with MEN1 on the basis of clinical, genetic and familial criteria (Supplementary Table 1) [2]. Interestingly, first manifestation of the patient was asymptomatic mediastinal mass by atypical 


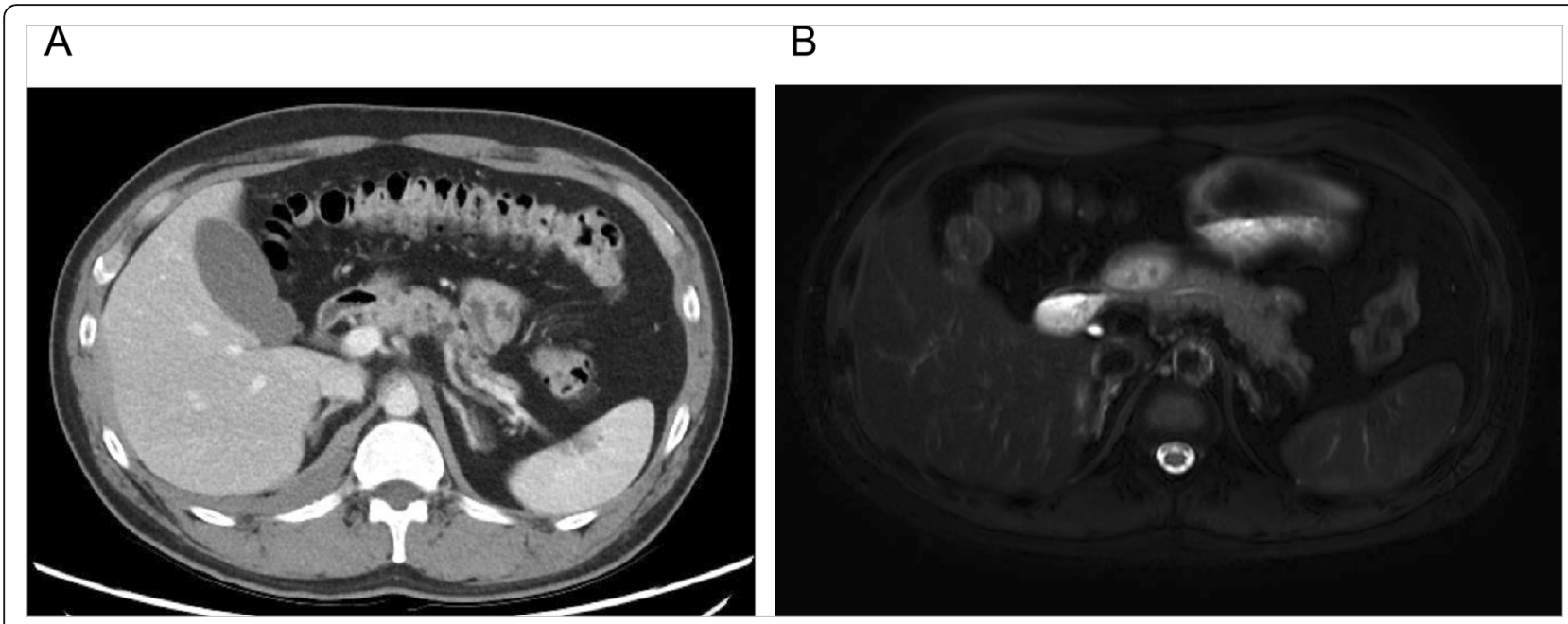

Fig. 3 a Abdominal CT showing multiple small hypodense lesions in the head and body of the pancreas. $\mathbf{b}$ Magnetic resonance imaging demonstrates a normal pancreas

thymic carcinoid tumor which is a rare entity in MEN1. MEN1 is an inherited tumor syndrome caused by inactivating heterozygous mutations of the MEN1 gene that affect the parathyroid glands, neuroendocrine tissues of gastroenteropancreatic origin, thoracic tracts, and the anterior pituitary gland [6]. Parathyroid tumors, resulting in primary hyperparathyroidism, are the most common feature of MEN1 and occur in approximately 95\% of patients, whereas pancreatic NETs occur in $40 \%$ and anterior pituitary tumors occur in 30\% [6].

Thymic carcinoid tumor is generally a late manifestation of MEN1 [7]; in a previous report, it was most commonly diagnosed as an anterior mediastinal mass usually found

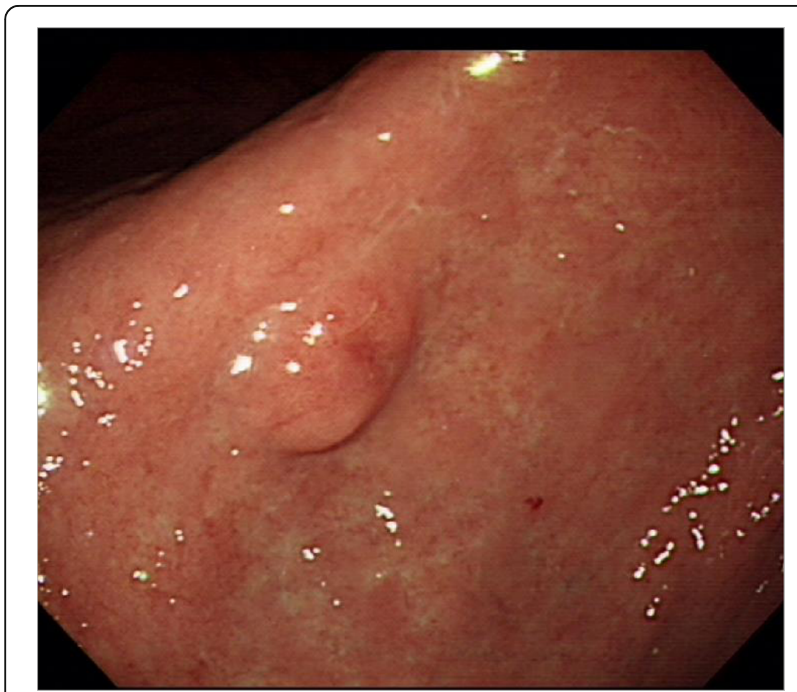

Fig. 4 Endoscopic image of a gastric neuroendocrine tumor at the antrum revealed a well circumscribed, submucosal mass with normal overlying mucosa on chest $\mathrm{x}$-ray or $\mathrm{CT}$ scans during periodic health examination, consistent with this case [8]. In a different series of patients with MEN1-associated thymic carcinoid tumor, the age of presentation was between 30 and 50 years, the patients were predominantly heavy smokers, and the disease had a predilection for men over women $[8,9]$. Despite its insidious onset, thymic carcinoid tumor is an important determinant of long-term survival in MEN1 patients, because MEN1-associated thymic carcinoid tumor leads to poor prognosis due to its more aggressive nature and strong potential for metastasis even after apparently radical excision $[5,8]$.

The unusual occurrence of MEN1 in this case was that the first presentation of the patient was asymptomatic huge thymic carcinoid, rather than a classical manifestation which is comprised of hyperplasia and/or tumors of parathyroid, pancreas, or anterior pituitary origin that occur at a high rate by the age 40 in the affected individuals [10]. Hypercalcemia was mild, although primary hyperparathyroidism is most common and early manifestation of MEN1. Moreover, the serum prolactin level of this patient was not high enough to suspect prolactinoma, and MRI imaging did not show the definite lesion. Pancratic lesions was also considered as benign fat infiltrations. Instead, he presented relatively rare MEN1-associated tumors that included thymic carcinoid ( $2 \%$ of estimated penetrance) and gastric NET (10\% of estimated penetrance) [11], with MEN1 mutation.

Treatment for each of the MEN1-associated endocrine tumors requires complete surgical resection, which is similar to treatment for respective tumors in non-MEN1 patients. However, the surgical outcomes of patients with MEN-1 associated tumors may not surpass those of patients with sporadic solitary tumors because MEN1associated tumors simultaneously occur at multiple sites, 


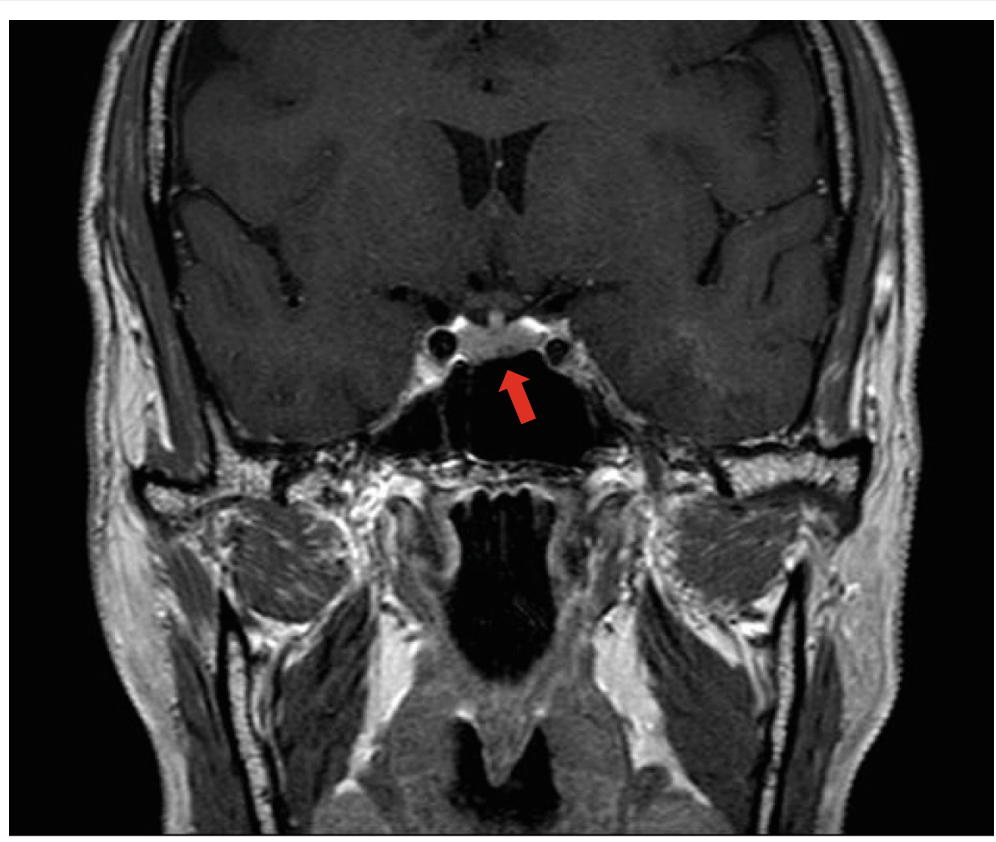

Fig. 5 Sella MRI (coronal T1-weighted postcontrast) showing a 0.3-cm-sized, delayed enhancing lesion of the pituitary gland, suggestive of a pituitary microadenoma (red arrow)
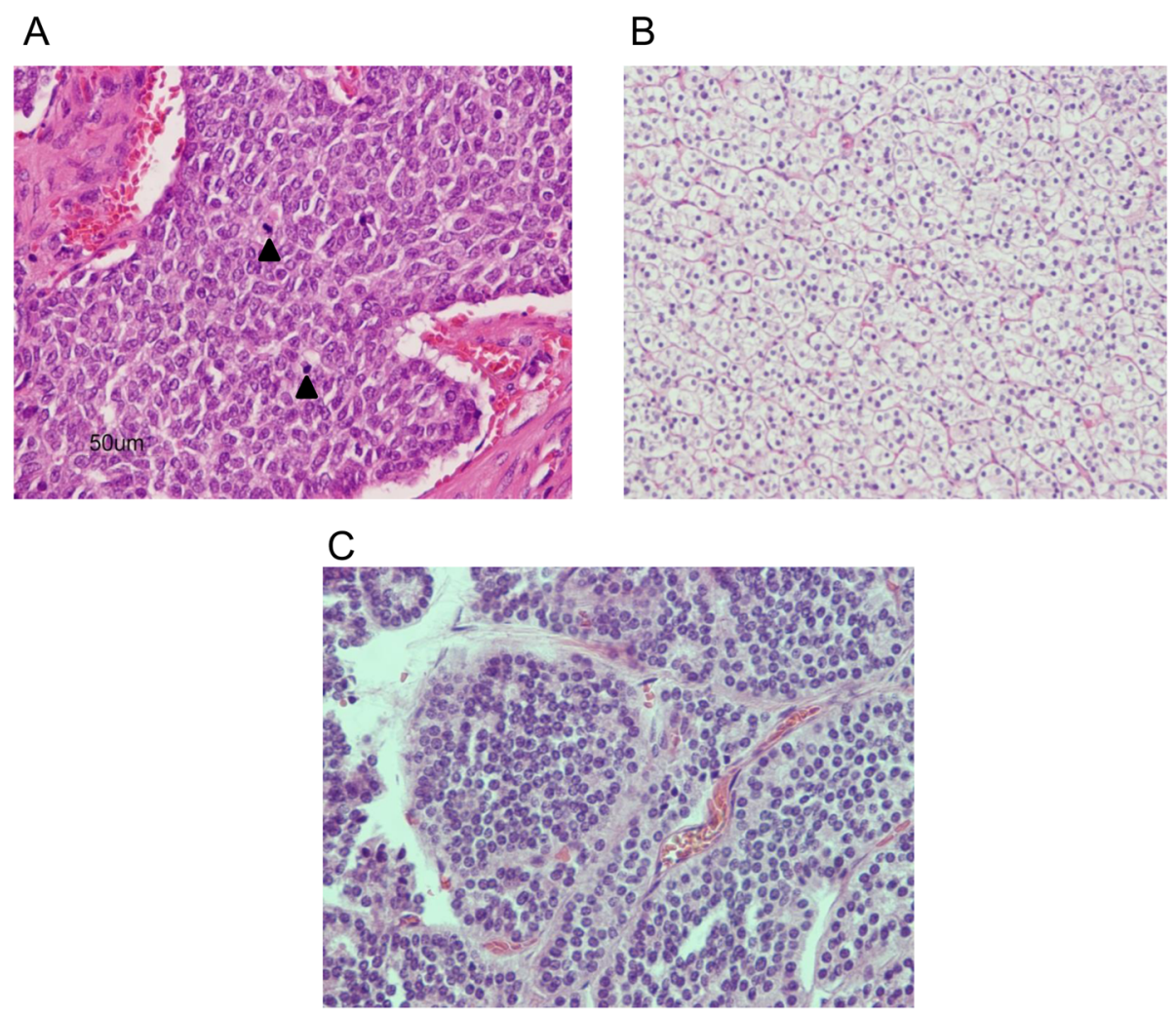

Fig. 6 Pathological results of surgical resection. a Thymic cancer: The tumor exhibited a solid growth pattern with 9 mitoses per 10 high-power fields without necrosis (hematoxylin-eosin stain $\times 100$ ). Black arrowhead indicates mitoses of carcinoid cells. $\mathbf{b}$ Water clear cells of parathyroid adenoma with minimal nuclear pleomorphism and have uniformly clear cytoplasm with numerous microvacuoles (hematoxylin-eosin stain $\times 100$ ). c Gastric neuroendocrine tumor with salt-and-pepper chromatin, amphophilic cytoplasm, and scant atypia (hematoxylin-eosin stain $\times 100$ ) 
have many occult metastatic lesions, and show more aggressive features [11]. Therefore, even prophylactic thymectomy should be considered in high-risk patients, such as male smokers or those with close relatives who present with this feature [8], to prevent development of thymic carcinoid tumor. Subtotal or total parathyroidectomy, definite treatment of primary hyperparathyroidism, is also recommended due to the high recurrence rate [11]. However, one overactive parathyroid gland in this patient was removed in the transcervical approach not to disturb the resection of huge mediastinal mass. The patient's serum PTH and calcium levels have been annually monitored after parathyroidectomy in order to detect any possible recurrence from the remaining three parathyroid glands.

It is noteworthy that early diagnosis of MEN1 is mandatory for identification and subsequent treatment at a very early stage for preventing malignant progression and metastases as well as clinical consequences of hormone overproduction-related syndromes, which are the main causes of mortality and morbidity of patients with MEN1 [12]. In this respect, genetic and biochemical screening in asymptomatic family members of patients with MEN1 are likely to be beneficial for a longer survival [11]. MEN1 mutation analysis should be undertaken in the index case, asymptomatic first-degree relatives of a known MEN1 carrier, and first-degree relatives of a MEN1 mutation carrier expressing familial MEN1 [5]. The patient in the present case had a missense mutation of the MEN1 gene (V215M on exon 3), which was reported in two prior MEN1 cases in Korea $[13,14]$. DNA sequencing was performed for the patient's 7-year-old son, and the same mutant gene was identified. Tumors have been reported in children with MEN1 by the age of 10 years [11], so we have been annually monitoring symptoms and performing biochemical tests on his son as well as the index patient.

In conclusion, the present study reported an asymptomatic MEN1-associated thymic carcinoid as the first manifestation of MEN1. All MEN1-associated endocrine tumors were successfully removed, and there was no evidence of tumor recurrence at postoperative 1 year. Systematic evaluations and close follow-up of other endocrine organs are needed in patients with thymic carcinoid tumor and MEN1 mutation.

\section{Supplementary Information}

The online version contains supplementary material available at https://doi. org/10.1186/s12902-021-00695-9.

Additional file 1: Supplementary Fig. 1. (A) Pedigree chart of the patient. The index patient and his son carry the same MEN1 gene mutation. (B) DNA sequencing shows a heterozygous missense mutation in exon 3 (p.Val215Met).
Additional file 2: Table S1. Diagnostic criteria of MEN1 ${ }^{*}[2]$

\section{Abbreviations}

MEN1: Multiple endocrine neoplasia type 1; CT: Computed tomography; PTH: Parathyroid hormone; BMD: Bone mineral density; MRI: Magnetic resonance imaging; NET: Neuroendocrine tumor

\section{Acknowledgements \\ None.}

\section{Authors' contributions}

Conceptualization: JJE and IKJ; Data curation: JEJ; Supervision: YCH, KYA, and HYC; Writing - original draft: JEJ; Writing - review \& editing: IKJ. All authors have read and approved the manuscript.

\section{Funding}

None.

\section{Availability of data and materials}

The datasets used and/or analyzed during the current study are available from the corresponding author on reasonable request.

\section{Ethics approval and consent to participate}

Informed consent for publication of clinical data was submitted by the patient and the images are published with the consent of the patient. It was reviewed and approved by established our Institutaional Review Boards (IRB No. 2018-07-023).

\section{Consent for publication}

Written informed consent was obtained from all patients whose details were discussed in the manuscript for publication of this case report and any accompanying images.

The patients gave written consent for their personal or clinical details along with any identifying images to be published in this study.

\section{Competing interests}

The authors have no competing interest to disclose.

Received: 27 August 2020 Accepted: 9 February 2021

Published online: 25 February 2021

\section{References}

1. Marini F, Falchetti A, Del Monte F, Carbonell Sala S, Gozzini A, Luzi E, et al. Multiple endocrine neoplasia type 1. Orphanet J Rare Dis. 2006;1:38.

2. Kamilaris CDC, Stratakis CA. Multiple endocrine Neoplasia type 1 (MEN1): an update and the significance of early genetic and clinical diagnosis. Front. Endocrinol. 2019. https://doi.org/10.3389/fendo.2019.00339.

3. Sakurai A, Suzuki S, Kosugi S, Okamoto T, Uchino S, Miya A, et al. Multiple endocrine neoplasia type 1 in Japan: establishment and analysis of a multicentre database. Clin Endocrinol (Oxf). 2012;76(4):533-9.

4. Ito T, Jensen RT. Imaging in multiple endocrine neoplasia type 1: recent studies show enhanced sensitivities but increased controversies. Int J Endocr Oncol. 2016;3(1):53-66.

5. Goudet P, Murat A, Binquet C, Cardot-Bauters C, Costa A, Ruszniewski P, et al. Risk factors and causes of death in MEN1 disease. A GTE (Groupe d'Etude des Tumeurs endocrines) cohort study among 758 patients. World J Surg. 2010;34(2):249-55.

6. Thakker RV. Multiple endocrine neoplasia type 1 (MEN1). Best Pract Res Clin Endocrinol Metab. 2010;24(3):355-70.

7. Carrera S, Garin I, Sancho A, Beristain E, Azkona E, López-Vivanco G, et al. Thymic carcinoid tumor as single manifestation of multiple endocrine Neoplasia type 1: a clue to suspect a Germline MEN1 mutation. Ann Clin Case Rep. 2017;2:1293.

8. Ferolla P, Falchetti A, Filosso P, Tomassetti P, Tamburrano G, Avenia N, et al. Thymic neuroendocrine carcinoma (carcinoid) in multiple endocrine neoplasia type 1 syndrome: the Italian series. J Clin Endocrinol Metabol. 2005;90(5):2603-9.

9. Singh Ospina N, Maraka S, Montori V, Thompson GB, Young WF Jr. When and how should patients with multiple endocrine neoplasia type 1 be 
screened for thymic and bronchial carcinoid tumours? Clin Endocrinol (Oxf). 2016;84(1):13-6.

10. Brandi ML, Gagel RF, Angeli A, Bilezikian JP, Beck-Peccoz P, Bordi C, et al. ConsensBrandi ML, Gagel RF, Angeli A, Bilezikian JP, Beck-Peccoz P, Bordi C, et al. Consensus: guidelines for diagnosis and therapy of MEN type 1 and 2 . J Clin Endocrinol Metabol. 2001;86(12):5658-71.

11. Thakker RV, Newey PJ, Walls GV, Bilezikian J, Dralle H, Ebeling PR, et al. Clinical practice guidelines for multiple endocrine neoplasia type 1 (MEN1). J Clin Endocrinol Metabol. 2012;97(9):2990-3011.

12. Giusti F, Marini F, Tonelli F, Brandi ML. Multiple endocrine neoplasia type 1. In: Principles of bone biology: Elsevier; 2020. p. 1293-306.

13. Choi YS, Bai YS, Ku BJ, Jo YS, Kim YK, Ro HK, et al. A case of multiple endocrine neoplasia type I with atypical clinical course. J Kor Endocr Soc. 2008;23(4):266-71.

14. Cha J, Kim JS, Han JS, Park YW, Kim MJ, Ku YH, et al. Multiple endocrine Neoplasia type 1 presenting with an invasive Giant Prolactinoma. Kor J Med. 2016;91(3):300-5.

\section{Publisher's Note}

Springer Nature remains neutral with regard to jurisdictional claims in published maps and institutional affiliations.

Ready to submit your research? Choose BMC and benefit from:

- fast, convenient online submission

- thorough peer review by experienced researchers in your field

- rapid publication on acceptance

- support for research data, including large and complex data types

- gold Open Access which fosters wider collaboration and increased citations

- maximum visibility for your research: over $100 \mathrm{M}$ website views per year

At $\mathrm{BMC}$, research is always in progress.

Learn more biomedcentral.com/submissions 